\title{
PELATIHAN PEMBUATAN MEDIA PEMBELAJARAN INTERAKTIF BAGI GURU-GURU DI KABUPATEN LOMBOK TIMUR
}

\author{
Oleh: \\ Atik Wintarti ${ }^{1}$ dan Abadi $^{2}$ \\ Jurusan Matematika FMIPA Unesa \\ 1atikwintarti@unesa.ac.id
}

\begin{abstract}
Abstrak
Pemanfaatan Teknologi Informasi dan Komunikasi (TIK) dalam bidang pendidikan diantaranya adalah untuk pembuatan media pembelajaran. Namun pada umumnya yang digunakan adalah media pembelajaran presentasi yang bersifat satu arah. Agar pembelajaran menarik diperlukan media pembelajaran interaktif yang bersifat dua arah sehingga guru dapat mengetahui umpan balik dari apa yang dipelajari peserta didiknya. Pascasarjana Universitas Negeri Surabaya, khususnya Tim Pengabdian Kepada Masyarakat (PKM), berusaha merintis kerjasama dengan Dinas Pendidikan Kabupaten Lombok Timur. Rintisan kerjasama tersebut dilakukan dengan mengadakan kegiatan PKM dengan sasaran guruguru sekolah menengah seperti Sekolah Menengah Pertama (SMP), Sekolah Menengah Atas (SMA), atau Sekolah Menengah Kejuruan (SMK) dalam pembuatan media pembelajaran interaktif bagi guru-guru di Kabupaten Lombok Timur.

Kegiatan pelatihan berjalan lancar dan peserta merasakan manfaat pelatihan pembuatan media pembelajaran interaktif karena selama ini hanya bersifat satu arah. Berdasarkan angket yang diisi peserta, pelatihan ini baru pertama kali dikenal peserta maka waktu yang disediakan masih terasa kurang. Tetapi hal ini dapat diatasi dengan melalukan konsultasi secara online. Peserta pelatihan adalah para Kepala Sekolah sehingga diharapkan dapat menyampaikannya pada guru-guru di sekolahnya.
\end{abstract}

Kata Kunci: pelatihan, media pembelajaran, interaktif

\section{Abstract}

One of the application of Information and Communication Technology (ICT) in the education scope is the use of learning media. But in general the teachers use a one-way presentation learning media. To make an interesting learning, it is needed a two-way interactive learning media so that the teacher know the feedback from what students learn. Pascasarjana Universitas Negeri Surabaya, especially this Team of Pengabdian Kepada Masyarakat (PKM), try to pioneer cooperation with the Dinas Pendidikan Kabupaten Lombok Timur. The pioneering of the collaboration was carried out by holding PKM activities with targets are middle school teachers such as Junior High Schools (SMP), Senior High Schools (SMA), or Vocational High Schools (SMK) in making interactive learning media for teachers in Lombok Timur area .

The training activities went fluently and the participants got benefit from the training in making interactive learning media because all this time they made it only one-way. According to the quesionare, the training was the first time for participants, they need more time. But this can be overcome by passing an online consultation. The training participants are principals so that they are expected to be able to convey it to the teachers in their schools.

Keywords: training, learning media, interactive

\section{PENDAHULUAN}

Berdasarkan Undang-Undang Nomor 14 Tahun 2005 tentang Guru dan Dosen pasal 10 ayat (1) disebutkan bahwa "Kompetensi guru sebagaimana dimaksud dalam pasal 8 meliputi kompetensi pedagogik, kompetensi kepribadian, kompetensi sosial, dan kompetensi profesional yang diperoleh melalui pendidikan profesi" (UU No.14, 2005). Dengan demikian guru diharapkan dapat merancang dan melaksanakan pembelajaran berdasarkan landasan pendidikan, teori belajar dan pembelajaran, menentukan strategi pembelajaran berdasarkan karakteristik peserta didik, kompetensi yang ingin dicapai serta materi yang diajarkan. Kompetensi profesional yang dituntut dari seorang guru adalah menguasai materi, struktur, konsep, dan pola pikir keilmuan dari pelajaran yang diampu serta mengembangkannya secara kreatif dan memanfaatkan Teknologi Informasi dan Komunikasi (TIK).

Pemanfaatan TIK dalam bidang pendidikan sangat banyak, diantaranya 
adalah untuk otomatisasi administrasi, pembuatan perangkat pembelajaran, media pembelajaran, evaluasi pembelajaran bahkan sebagai sarana pembelajaran interaktif (Suryono, 2013). Pascasarjana Universitas Negeri Surabaya, khususnya Tim Pengabdian Kepada Masyarakat, berusaha merintis kerjasama dengan Pemerintah Kabupaten Lombok Timur. Rintisan kerjasama tersebut dilakukan dengan mengadakan kegiatan Pengabdian Kepada Masyarakat (PKM) dengan sasaran guru-guru sekolah menengah seperti Sekolah Menengah Pertama (SMP), Sekolah Menengah Atas (SMA), atau Sekolah Menengah Kejuruan (SMK) dalam pembuatan media pembelajaran interaktif bagi guru-guru di Kabupaten Lombok Timur.

Untuk itu perlu dilakukan suatu kegiatan dalam bentuk PKM yang bertujuan untuk memberikan pelatihan pemanfaatan TIK untuk pembuatan media pembelajaran interaktif. Karena itulah Tim PKM Pascasarjana mengadakan kegiatan PKM dengan judul: Pelatihan Pembuatan Media Pembelajaran Interaktif Bagi Guru-guru di Kabupaten Lombok Timur.

\section{METODE}

Pada kegiatan PKM kali ini, Tim bekerja sama dengan Dinas Pendidikan Kabupaten Lombok Timur sebagai Mitra yang berperan serta dalam hal menyediakan:

1) tempat pelatihan dan

2) semua peralatan yang diperlukan selama pelatihan berlangsung

Pada waktu mendiskusikan permasalahan mitra terdapat hambatan yaitu masalah waktu yang disediakan tidak mencukupi untuk pelatihan pembuatan media pembelajaran interaktif yang menggunakan Macro Media Flash CS6 sebagaimana yang diberikan pada mata kuliah Media Pembelajaran di Unesa. Kemudian diusulkan untuk memberikan pelatihan pembuatan media pembelajaran interaktif menggunakan PowerPoint dengan Macro Visual Basic for Application karena guru-guru umumnya sudah bisa membuat presentasi untuk media pembelajaran namun tidak interaktif (Bimo, 2016).

Tim pelaksana PKM melakukan koordinasi dengan Dinas Pendidikan dan Kebudayaan Kabupaten Selong dan disarankan untuk bekerjasama dengan Musyawarah Kerja Kepala Sekolah (MKKS) Kabupaten Lombok Timur. Setelah koordinasi disepakati pelatihan ini akan diikuti para kepala sekolah supaya dapat disampaikan pada guru-guru SMP dan
SMA di sekolahnya. Sedangkan untuk tempat pelatihan, SMA Negeri 1 Selong bersedia menjadi tuan rumah karena mempunyai fasilitas laboratorium komputer yang cukup memadai.

Adapun kegiatan PKM ini dilaksanakan dengan langkah-langkah sebagai berikut:

1) memberikan teori media pembelajaran interaktif;

2) memberikan pelatihan (workshop) pembuatan media pembelajaran interaktif;

3) mempresentasikan hasil pembuatan media pembelajaran interaktif oleh peserta pelatihan.

Prosedur yang dilakukan Tim PKM selama melakukan pelatihan adalah:

1) melakukan koordinasi dengan Dinas Pendidikan Kabupaten Lombok Timur;

2) mendiskusikan langkah umum pelatihan yaitu: teori, workshop dan presentasi

3) melakukan refleksi pelatihan dengan cara memberi angket.

Teknik pengumpulan data yang dilakukan adalah presentasi media pembelajaran interaktif yang dihasilkan peserta dan angket.

\section{HASIL DAN PEMBAHASAN}

Kegiatan PKM ini dilaksanakan di SMA Negeri 1 Selong Lombok Timur pada tanggal 3 - 5 Agustus 2018. Pada hari pertama dilakukan Pembukaan PKM oleh Pascasarjana Universitas Negeri Surabaya dilanjutkan dengan Pemberian Materi Pelatihan tentang Pembuatan Media Pembelajaran Interaktif. Peserta pelatihan terdiri dari 16 Kepala Sekolah SMP dan SMA dari daerah Lombok Timur. Diharapkan setelah pelatihan, para kepala sekolah dapat menyampaikan apa yang telah diperolehnya pada guru-guru di sekolah masing-masing. Kegiatan pada hari pertama ditunjukkan pada Gambar 1.

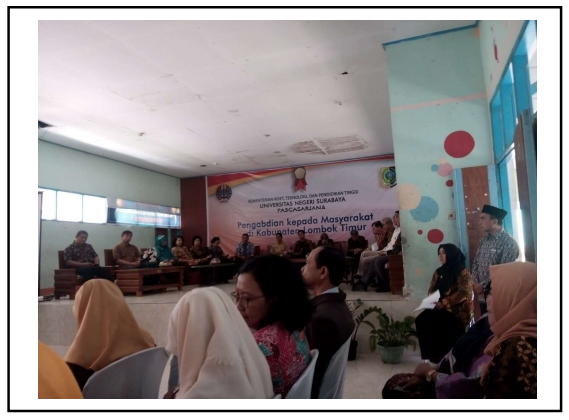

Gambar 1. Pembukaan PKM

Pada hari kedua dilakukan workshop dan pendampingan dalam pembuatan media pembelajaran interaktif berbasis TIK. Pada kegiatan ini digunakan Microsoft Power Point 
yang sudah biasa digunakan oleh para peserta dengan menambahkan fitur Macro Visual Basic for Application (VBA) sehingga presentasi yang digunakan dapat menerima input yang diberikan (Harini, 2010). Dengan demikian presentasi tidak hanya dilakukan satu arah tetapi dapat interaktif dua arah antara guru dan siswa. Diharapkan dengan menggunakan media pembelajaran interaktif ini siswa dapat mempelajari materi dengan baik karena pemahaman siswa mengenai materi dapat dilihat guru berdasarkan input atau respon yang diberikan siswa. Suasana workshop dan pendampingan disajikan pada Gambar 2. berikut.

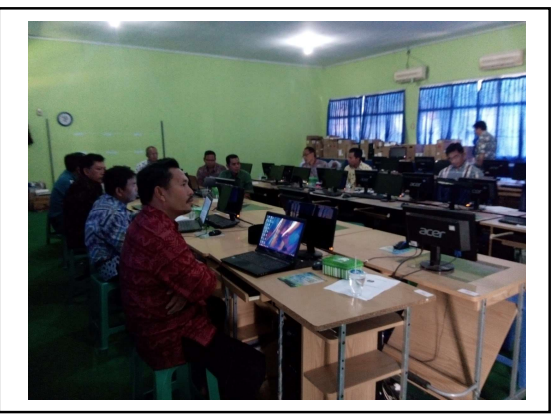

Gambar 2. Suasana Workshop

Pada hari terakhir dilakukan presentasi tentang media pembelajaran interaktif berbasis TIK yang dihasilkan oleh peserta pelatihan. Karena waktu pembuatan media pembelajaran interaktif terbatas dan peserta baru mengenal fitur VBA maka tidak semua peserta dapat menghasilkan media pembelajaran yang dimaksud. Namun hal ini akan diatasi dengan mengirimkan media yang dihasilkan melalui email karena media berbasis TIK. Adapun beberapa hasil media pembelajaran dari peserta dapat disajikan pada Gambar 3. berikut.

Gambar 3a. Media Biologi

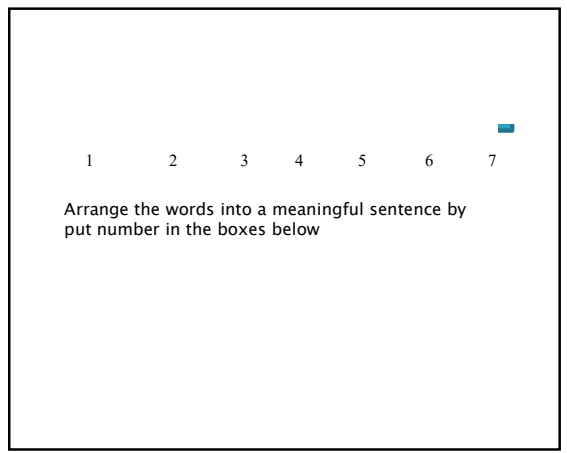

Gambar 3b. Media Bahasa Inggris

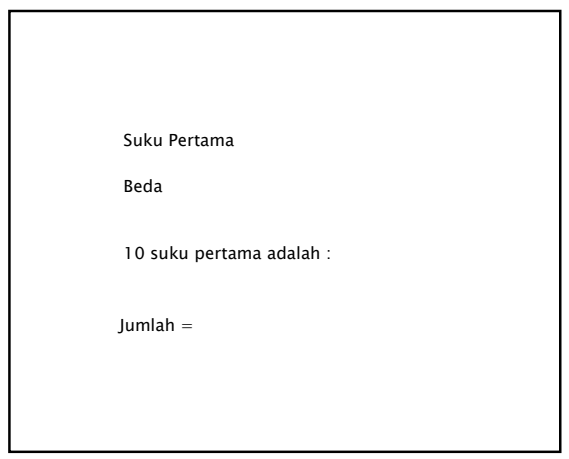

Gambar 3c. Media Matematika

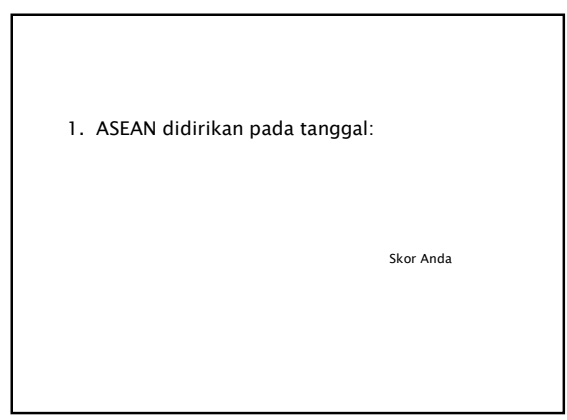

Gambar 3d. Media IPS

Peserta sangat antusias mengikuti pelatihan pembuatan media pembelajaran interaktif menggunakan PowerPoint yang sudah mereka pakai untuk presentasi. Banyak peserta yang merasa tertarik karena selama ini PowerPoint hanya digunakan untuk menyampaikan materi pelajaran secara satu arah.

Namun waktu untuk membuat media pembelajaran pada waktu workshop bagi peserta dirasakan tidak mencukupi. Peserta hanya mencoba membuat media pembelajaran interaktif seperti yang ada pada materi pelatihan. Untuk mengatasi hal ini peserta dapat membuat media pembelajaran sesuai bidang studi masing-masing setelah pelatihan selesai. Apabila ada permasalahan yang timbul, peserta dapat berkonsultasi 
dengan tim pelaksana PKM melalui email atau media WhatsApp.

Setelah pelaksanaan pelatihan, Tim PKM memberikan angket kepada peserta.
Berdasarkan hasil isiaian angket, pendapat peserta dapat disimpulkan pada Tabel 1 .

Tabel 8. Hasil Angket Peserta Pelatihan Media Pembelajaran Interaktif

\begin{tabular}{|c|c|c|}
\hline No. & Butir Angket & Hasil \\
\hline 1. & $\begin{array}{l}\text { Apakah Anda pernah mengikuti } \\
\text { pelatihan sejenis? Jika pernah, } \\
\text { sebutkan }\end{array}$ & $100 \%$ belum pernah \\
\hline 2. & $\begin{array}{l}\text { Apakah menurut Anda pelatihan } \\
\text { ini ada manfaatnya bagi Anda? } \\
\text { Jika ada, sebutkan }\end{array}$ & $\begin{array}{l}\text { 87,5\% menyatakan bermanfaat } \\
\text { a.l: membantu guru dalam pembelajaran, } \\
\text { meningkatkan motivasi siswa, menambah } \\
\text { pengetahuan tentang PowerPoint, dapat membuat } \\
\text { media pembelajaran lebih menarik. } \\
12,5 \% \text { tidak menjawab }\end{array}$ \\
\hline 3. & $\begin{array}{l}\text { Apakah yang Anda harapkan dari } \\
\text { pelatihan ini? }\end{array}$ & $\begin{array}{l}\text { Jawaban a.l.: bisa membuat media pembelajaran } \\
\text { yang menarik, dapat meningkatkan kompetensi } \\
\text { guru, bisa ditularkan ke guru-guru, dilakukan } \\
\text { pelatihan lagi, mampu mengimplementasikan }\end{array}$ \\
\hline 4a. & $\begin{array}{l}\text { Kritik atau saran terhadap materi } \\
\text { pelatihan }\end{array}$ & $\begin{array}{l}\text { Jawaban a.l.: lebih banyak lagi, padat dan singkat, } \\
\text { bermanfaat }\end{array}$ \\
\hline 4b. & $\begin{array}{l}\text { Kritik atau saran terhadap } \\
\text { pelaksanaan }\end{array}$ & $\begin{array}{l}\text { Jawaban a.l: cukup baik, waktu kurang, perlu } \\
\text { diadakan lagi }\end{array}$ \\
\hline $4 c$ & $\begin{array}{l}\text { Kritik atau saran terhadap nara } \\
\text { sumber }\end{array}$ & $\begin{array}{l}\text { Jawaban a.I.: Menguasai, Terlalu cepat, Baik, } \\
\text { Mantap }\end{array}$ \\
\hline
\end{tabular}

Setelah pelatihan selesai dilakukan terjadi gempa di daerah Lombok dengan berkekuatan 7 skala Richter pada pukul 19.46 WITA disusul gempa-gempa berikutnya. Hal ini menyebabkan para peserta pelatihan tidak dapat membuat media pembelajaran interaktif apalagi menyampaikan materi pelatihan pada guru-guru di sekolahnya.

\section{SIMPULAN DAN SARAN}

\section{Simpulan}

Berdasarkan Hasil dan Luaran yang Dicapai di atas, kegiatan PKM dengan judul Pelatihan Pembuatan Media Pembelajaran Interaktif Bagi Guru-guru di Kabupaten Lombok Timur ini telah dilaksanakan pada tanggal 3 - 5 Agustus 2018 di SMA Negeri Selong, Lombok Timur dengan peserta 16 Kepala Sekolah SMP dan SMA sesuai dengan rencana yang diajukan.

Peserta sangat antusias dalam menerima materi pelatihan karena selama ini hanya menggunakan PowerPoint hanya untuk presentasi biasa yang tidak interaktif. Namun waktu untuk workshop dirasakan kurang oleh kebanyakan peserta sehingga mereka hanya mencoba membuat media pembelajaran seperti yang ada pada materi pelatihan. Untuk pembuatan media pembelajaran interaktif sesuai dengan mata pelajaran yang diampu akan dilakukan setelah pelatihan dan akan ditularkan kepada guru-guru di sekolahnya.

Setelah kegiatan PKM ini dilakukan terjadi gempa berkekuatan 7 skala Richter di pulau Lombok pada tanggal 5 Agustus 2018 pada pukul 19.46 WITA disusul beberapa gempa berikutnya. Hal ini menyebabkan para peserta pelatihan tidak dapat membuat media pembelajaran interaktif apalagi menyampaikan materi pelatihan pada guruguru di sekolahnya.

\section{Saran}

Berdasarkan kesimpulan di atas penulis menyarankan agar dilakukan pelatihan lagi walaupun jarak jauh jika keadaan memungkinkan karena setelah tanggal 5 Agustus 2018 masih ada gempa susulan.

\section{DAFTAR PUSTAKA}

Bimo, Djoko S. 2016. Langkah Praktis Pembuatan Media Presentasi Yang Efektif dan Interaktif untuk Pembelajaran, Prosiding Temu IImiah Nasional Guru VIII Harini, Asih Widi. 2010. Effektif dan Powerfull Presentation with Powerpoint. Yogyakarta 
Suryono, H. D. 2013. Peranan Teknologi Informasi dan Komunikasi (ICT) dalam Peningkatan Proses Pembelajaran yang Inovatif, Seminar Nasional Pendidikan \& Saintec UMS.

UU Nomor 14 Tahun 2005 Tentang Guru dan Dosen

(2017). Pedoman Pengabdian Kepada Masyarakat Kebijakan (PKM) Fakultas/Jurusan/Prodi/Mandiri. Lembaga Penelitian dan Pengabdian kepada Masyarakat Universitas Negeri Surabaya. 